\title{
The multi-level policy learning of environmental policy: insights from Izmir
}

\author{
Koray Velibeyoğlu ${ }^{a}$ and Onur Mengi ${ }^{b}$ \\ aDepartment of Urban and Regional Planning, Izmir Institute of Technology, Izmir, Turkey; \\ ${ }^{b}$ Department of Industrial Design, Izmir University of Economics, Izmir, Turkey
}

\begin{abstract}
A European Union (EU) membership perspective is important for Turkey's harmonization with EU standards, which could have positive outcomes especially in the area of smart environmental management. However, as recent political developments suggest, Turkey is losing hope of full EU membership, and is searching for alternatives, such as privileged partnership. Active contributions of city-level good practices are urgently needed. Policy learning is a part of this process, and an emergent result of ever-changing negotiations involving a multiplicity of actors at the multi-level perspective (MLP). The present study investigates the glocal environmental policy of Izmir, via a review of recent governmental environmentally sensitive local innovative practices. The findings reveal that innovative environments that increase learning-by-doing and learning-by-using will become critical for environmental policy learning in Izmir and perhaps beyond.
\end{abstract}

ARTICLE HISTORY Received 10 October 2017; Accepted 31 May 2018

KEYWORDS Socio-technological transitions; multi-level perspectives; environmental policy learning; local politics; Izmir

\section{Introduction}

Environmental policy making in Turkey has mostly been positioned at the national level, however, cities have taken active positions and extended their networks with each other, as well as with the European Union (EU) and other international actors. The Covenant of Mayors (CoM), the world's largest urban climate and energy initiative, is a clear example of how international coalitions of cities can cooperate for environmental protection of our world. Following this lead, environmental policy has become more 'glocal' in Turkey, thereby making more abstract global environmental issues meaningful to society at the local level.

While the policy learning process continues to be interpreted through the national context and government ministries and is influenced by actors such 
as the EU, local actions and initiatives are often quite important, particularly so as they may have more of an impact on individual citizens. The role of cities in environmental policymaking, however, is still neglected, and studies in this field are almost completely lacking. There is a major need to consider all formal and informal institutions at different levels, from local government projects and incentives to international environmental policies and multilateral environmental agreements, as potential instruments for resolving problems. This present research explores the wisdom of adopting a multi-level perspective (MLP), raising in particular the question of whether multi-level policy learning is possible, especially as environmental problems are often seen as global issues and are framed as needing global action to tackle the problem. Complex and context-relevant solutions are needed for a multileveled environmental management approach. However, management of environmental issues necessitates both formal administrative activities and informal mechanisms and institutions.

Izmir, a major city on Turkey's Aegean coast, has recently tried to brand itself as environmentally sensitive metropolitan city and has made conscious efforts to protect vulnerable cultural and natural assets. This article examines Izmir's glocal environmental policy from an MLP. The Izmir Metropolitan Municipality's recent environmentally sensitive local innovative practices are elaborated within a glocal context. This article also identifies the possible implications of EU-induced policy learning processes by illustrating the case of the city's cycling policy. The case of Izmir shows that it is struggling with the variety of problems, and is generally unable in to find ways within existing regulatory frameworks to support multi-level environmental policies.

Izmir illustrates a unique case with a vast range of recently made improvements, including membership in EuroVelo (cycling) networks, and possesses natural and cultural richness and immense tourism potential. İzmir was the first city in Turkey to be included in EuroVelo. In case of cycling, relations with local governments are being revisited and redefined, along the international coordination to ensure greater coherence in various policies and to seek new opportunities for efficient policy making. Cycling is an example of an active transport system, which are non-fuel-consuming and non-polluting and well-regarded in health, environmental and transportation fields. Bicycles are low-carbon vehicles with zero-emissions, relatively fast, and costeffective. ${ }^{1}$ Cycling also has great potential to enable people to incorporate physical activity into their lifestyles and thus reduce direct and indirect health care costs. ${ }^{2}$ There are causative associations between increased physical activity and reduced mortality, ${ }^{3}$ so that active transportation systems have considerable impact on physical activity and health outcomes. Cycling in particular is regarded as an effective way to promote more healthy urban life in developed countries. ${ }^{4}$ Additionally, the use of bicycles enables a decrease in the number of motor vehicles, thereby reducing traffic congestion, lowering 
the speed of fluid traffic, and significantly reducing atmospheric pollution. Previous case studies identify some environmental benefits as being positively linked to cycling, which can be promoted by dedicated cycle routes or paths, separation of cyclists from other traffic, high population density, short trip distances, and widespread proximity to a cycle path or green space. ${ }^{5}$ Cycling is a good case for understanding environmental policy learning, since there is an opportunity to create a deliberative setting via EU-induced learning processes, rather than a reactive one.

This article aims to describe and analyze the development of different cycling projects in Izmir, one of the most dynamic cities in Turkey. It has four parts. The first part focuses on the MLP, as developed and exploited by socio-technological transitions theory. The second part elaborates on transition management of glocal issues and the multi-level nature of environmental problems. The third part presents the cycling case in Izmir. In the case study, the analysis includes discussion of Izmir's environmentally sensitive projects analyzed through the MLP, and evaluations are made based on the environmental policy learning experience of Izmir in the light of theoretical insights and recent practical implementations. It concludes with further implications of Izmir's policy learning, and discusses cross-fertilization to other related fields of environmentally sensitive project implementations.

\section{Socio-technological transitions theory and the multi-level perspective}

The idea of a socio-technical regime was introduced in reference to Nelson and Winter's initial definition of a technological regime, namely 'the whole complex of scientific knowledge, engineering practices, production process technologies, product characteristics, skills and procedures, and institutions and infrastructures that make up the totality of technology. ${ }^{6}$ This definition has been expanded and redefined as interacting processes between heterogeneous institutions, a network that 'creates the structural patterns that shape innovation and creates trajectories of social development. ${ }^{77}$ Socio-technical transition suggests reconfiguration procedures for technology development and adjustment processes in science, industry, markets, policy, and culture. ${ }^{8}$ Such reconfiguration becomes crucial for the establishment of new paradigms incorporating the regime of production and use of technology. ${ }^{9}$ This process provides segmentation and decentralization of policy making in socio-technical systems regarding increasing complexity of management tasks. Such complex environments include not only firms or governmental bodies, but also other social groups, such as users, policy makers, specialinterest groups and civil society actors. Early works on socio-technical transition focuses on MLP, transition management, and strategic niche management. According to Geels and Schot, ${ }^{10}$ there are four distinct types of 
transition pathways (substitution, reconfiguration, de-alignment and re-alignment, transformation), distinguished by temporal orientation and the nature of multi-level interactions. The substitution path refers to emerging niche innovations that replace existing socio-technical systems. The reconfiguration path is the adoption process of niche innovations into the existing system. The de-alignment and re-alignment paths follow strong landscape or environmental changes (e.g. climate change), leading to current system breakdown (de-alignment), followed by a gradual re-alignment with a series of niche innovations. Finally, the transformation path produces changes in system elements designed to ease the problems and pressures on the current sociotechnical system.

The fundamentals of the MLP encompass transitions which are non-linear processes occurring at the intersection of multiple developments at three different levels: niches, regimes, and landscape. Niches are described as a ground for radical innovations, while socio-technical regimes are for the establishment of practices and associated rules. On the other hand, the socio-technical landscape is exogenous to increasing structuralization of activities in local practices. ${ }^{11}$ Such 'leveled' perspectives suggest heterogeneous configurations in a nested hierarchy with regimes being embedded within landscapes, and niches existing inside or outside regimes. ${ }^{12}$ However, informal bodies such as groups, platforms, and communities are likely be weakened by bottlenecks in a silo model of public administration. The silo metaphor occurs when a team or department carries out shared tasks, but takes its power and status from its wider group. Silos are regarded as a compartmentalization metaphor in organizational systems. ${ }^{13}$ For units with their own management and talent, it is also a metaphor that refers to a lack of motivation and a lack of collaboration and communication with other units. ${ }^{14}$ A major weakness of the silo mentality in public administration is that it may bring disruption in community engagements and also in operations.

In such climate, learning is the most important process in an innovation system. The literature on niche-innovation emphasizes learning as one of the key outcomes of internal processes alongside the adjustment of visions and building of social networks. Learning involves knowledge on various dimensions, such as organization, user behavior, infrastructure requirements, policy instruments and symbolic meanings. ${ }^{15}$ The DUI-mode of learning (Doing, Using and Interacting) in contrast to the STI-mode (Science, Technology and Innovation) is suggested as an alternative approach. ${ }^{16}$ This posits the role of tacit knowledge, power of localities, and experience-based innovation strategies. Policy learning is important for public sector innovation. Additionally, there are two different forms of policy learning. Instrumental learning refers to lessons about the viability of policy instruments or implementation designs. It concerns technical learning about instruments, 
which occurs when an actor learns how to cope with a problem without the need to change interests or preferences. Social learning, on the other hand, entails lessons about the social construction of policy problems, the scope of policy, or policy goals. It covers learning about guiding principles, values, norms, responsibilities, goals, and the (re) framing of issues in terms of causes and effects. In this sense, social learning in policy making is closer to the DUI-mode of learning in innovation studies. ${ }^{17}$

\section{Transition management of the glocal and the multi-level nature of environmental problems}

Environmental policy faces a range of challenges, such as climate change, pollution, drought, loss of biodiversity, and water depletion, all of which involve complex systems of closely interacting physical, biological, and social processes as well as an active participation of multiplicity of actors. A multilevel perspective on environmental problems requires a governance approach that aims to facilitate and accelerate sustainability transitions among multidimensional and multi-actor contexts. Many environmental resources are regarded as glocal in the sense that they provide various ecosystem services located at different scales. ${ }^{18}$ Despite the increasing interaction of diverse people, cities, or nations at the international level, driven by the increasing flow of money, ideas, and culture internationally, globalization instantaneously creates trends toward cultural homogenization. At the same time, globalization urges people to recognize their ethnic or nationalities. Emerging out of these contradicting tendencies is the concept of 'glocalization'. Glocalization refers to the simultaneous presence of global and local regimes, which transcend, overlap or intersect. First used in the 1980s, glocalization was conceptualized by Roland Robertson in the analysis of local response to global pressures, and defined as 'the simultaneity-the co-presence-of both universalizing and particularizing tendencies. ${ }^{19}$ Therefore, this article adopts the notion of the glocal links global public policy to local (municipal) governments.

\section{Case study: Izmir's environmental policy learning from the cycling case}

Izmir is a metropolitan city in western Turkey with a surface area of 12.019 $\mathrm{km}^{2}$ and a population of 4.2 million, making it the third largest city in Turkey. As a port, Izmir (once known as Smyrna) has served as Anatolia's gate to the west for millennia. In the Ottoman period, the city's cosmopolitan population and rich trade potential created a distinctive character. At the turn of the last century, however, Izmir entered into a period of recession in which the construction of various infrastructure and environmental projects 
decelerated due to the central government's inability to provide the expected support. This led to the development of local strategies and niche projects, deriving from the different localities and capabilities of the city.

Currently, an average 1.8 million people use urban transportation daily in Izmir. Although bicycle transportation is used by only 2.5 percent of the population, the Metropolitan Municipality implemented a project in 2009 called 'Time to Ride a Bicycle' to provide active transportation systems and make bicycle use widespread. Since 2013, bicycle facilities have been provided and integrated with metro and light rail systems. In the Izmir Transportation Main Plan, a continuous bicycle track is planned on the north side of the city, mainly following the shoreline. The total length of the track will extend $100 \mathrm{~km}$ to the southwest, to allow use of bicycles in daily life and increase the cycling network in line with current needs. Along the shoreline, rental units have been planned at 29 sites, and communication screens have been placed in certain public transportation nodes. ${ }^{20}$

EuroVelo is a long-distance cycling network of 16 routes consisting at present of almost 45,000 km of bike paths. EuroVelo is regarded as sustainable transportation model supported by the European Parliament's Committee on Transport and Tourism. In October 2017, the European Cyclists Federation (ECF) approved İzmir Metropolitan Municipality's application to participate in EuroVelo, with 16 different routes that connect Bergama and Selçuk districts on the UNESCO World Heritage list. The ECF will officially declare Turkey in the system of EuroVelo routes in 2019. Until then, further preparations will require different levels of policy implications and implementations concerning the tourism sector, local business owners, nongovernmental organizations and district mayors for information and publicity of the routes. ${ }^{21}$

This study employs local governments and cities as the units of analysis. The main assumption here is that bottom-up processes solving environmental problems at the local level have a strong transition effect in changing national rule sets and routines in the long run. In other words, MLP promotes social learning.

\section{Methodology}

The present research questions whether multi-level policy learning is actually possible. This study employs environmental policy learning in a multi-level understanding. At the global or international level, policy learning originates from international organizations such as the EU and World Bank through various environmental projects, as in the case of Izmir. At the local level, niche innovations are scrutinized using MLP within the frame of learning in the innovation management literature. The impact of combination global and local level efforts constitutes glocalization of environmental policy 
making in the city. This phenomenon is exemplified by the case of cycling policy in metropolitan Izmir.

In the following section, the analyses will elaborate system innovations through the development of MLP to include three levels of conceptualization of transitions proposed in previous studies: ${ }^{22}$

- Landscape (global/macro level) refers technological trajectories that are situated in a sociotechnical landscape, consisting of a set of deep structural trends.

- Regime (glocal/meso level) posits established practices of a given system /set of rules. Sociotechnical configurations result from the linkages between heterogeneous elements (patchwork of regimes).

- Niche (local/micro level) represents local innovations that are pioneers of behavioral and then system change. Local policies for up-scaling niche innovations are key to glocal, city-level good environmental practices. Niche level refers to the level of individual (or small group) innovative practices.

\section{Analysis of multi-level perspectives}

The general condition of environmental problems and governance of recent environmental projects/initiatives of Izmir are analyzed according to a multi-level perspective. Macro Level of analysis is characterized by global push: water, food and energy nexus creating the risk of resource depletion and climate change. The motivation here is to follow global trends, and to act together, forming a part of planetary solutions. Meso level indicates glocal flux for the implementation of large-scale environmental projects. In transportation, for example, the socio-technical regime is in a transition towards a greener, more circular economy. Micro level denotes local push (civil society's role in transition), searching for novel solutions to urban environmental problems within a multi-actor framework.

\section{Macro level analysis}

In the context of landscape pressure, and largely due to the acquis, Turkey has taken significant steps to promote renewable energy, targeting at least 30 percent of electricity from renewable resources by $2023 .{ }^{23}$ Aside from national and supranational conventions, an international coalition of cities has arisen worldwide to formulate environmental policy. The CoM is an important example of a broad coalition against climate change. Members of CoM cover 6,663 signatory towns, ranging from villages to major metropolitan areas including London and Paris. They have committed to adopting an integrated approach to climate change mitigation and adaptation. Members are required to develop a Sustainable Energy Action Plan (SEAP), with the aim 
of cutting $\mathrm{CO}_{2}$ emissions by at least 20 percent by 2020, and, more recently, Climate Action Plans, aiming to cut $\mathrm{CO}_{2}$ emission by 40 percent by $2030 .{ }^{24} \mathrm{In}$ Turkey, Izmir's leading efforts in terms of CoM membership (4 of Turkey's 10 members are in the Izmir area) represent such a global positioning. Signatory districts in Izmir, namely Bornova, Karşıyaka and Seferihisar, and the metropolitan municipality have declared a target of cutting 20 percent $\mathrm{CO}_{2}$ emission by 2020, and are working on climate action plans for 2030. However, these efforts are not reflected by national contexts. Most importantly, industry and agriculture, responsible for a large proportion of $\mathrm{CO}_{2}$ emissions, are not included in SEAP as they are non-municipal activities. At the national level, Turkey views emissions mitigation efforts as conflicting with its developmental policies, and has not ratified the Paris Agreement. Thus, Turkish members of the CoM are more ambitious than the national objectives and priorities in climate change mitigation and adaptation.

\section{Meso level analysis}

The EU agenda aims for a more sustainable mobility system, designed to improve the environmental performance of transport. A transition to sustainable mobility implies an understanding that small incremental steps are insufficient to achieve the necessary reduction in transport-related pressures on the environment. Izmir has environmentally fragile local assets, and is prone to hazardous environmental conditions, such as earthquakes, extreme drought seasons, frequent flooding, decreasing surface waters and ground water tables, and loss of natural areas. The city's water resources are very limited, with average consumption per person of only about 639 $\mathrm{m}^{3} /$ year. A fast growing and densely urbanized city, Izmir presents a somewhat negative example of high $\mathrm{CO}_{2}$ emission per capita, 5.31 tons per year. ${ }^{25}$ This emphasizes that urban green areas have an important role in mitigating the effects of climate change, such as counteracting carbon emissions. Unfortunately, Izmir suffers lack of sufficient green spaces and street trees. Nevertheless, the Izmir Metropolitan Municipality ranks high in terms of environmental investments in Turkey. According to 'Sustainability Research of Turkey's Sustainable Cities' [Türkiye’nin Şehirleri Sürdürülebilirlik Araştırmasl], İzmir leads a total of 81 cities in terms of environmental quality and natural resources sub-indexes. Objective criteria of sustainability indicators illustrate that the city is in the first rank in terms of environmental performance and quality of life. ${ }^{26}$

In Izmir's SEAP, urban transportation accounts for nearly 20 percent of all carbon emissions: it is aimed to decrease this to 15 percent by the year 2020 . To this end, the total share of public transportation, cycling and walking needs to increase dramatically. Local initiatives also have to be highly influential tackling the growing city's problems and in public infrastructure requirements for the environment. Due to the municipality's higher fiscal credibility, a new 
generation of public sea transportation fleet, and citywide tramlines, an intelligent transportation system is emerging, supported by multilateral development banks and funds from organization such as the European Bank for reconstruction and Development. Additionally, the municipality has begun to renew the citywide transportation master plan, and will be able to achieve a sustainable urban mobility plan with the technical support of World Bank. To this end, a sustainable logistics plan, and walking and cycling master plan have been launched, aligned with EU-funded grant programs. For instance, Izmir has been appointed as an exchange city in EU Horizon 2020 Flow Project, which aims to increase the proportion of walking and cycling in urban transportation.

\section{Micro level analysis}

At the micro level, there are pioneers of behavioral change in Izmir, including environmentalists reacting to insensitive renewable energy investments and cyclists demanding more pedestrian and bicycle friendly streets and infrastructures. The first wave of cases started with EU projects, which then influenced local activities and initiatives. The Izmir Peninsula Sustainable Local Development Strategy (2014-2023) recommended a priority implementation action, which included joining the European Cycling Federation's EuroVelo. To this end, a voluntarily organized study group has been established, under the moderation of the metropolitan government, to develop the further legitimacy of the EuroVelo application by enhancing cycling initiatives throughout the city. To increase the efficiency and recognition of this effort, the 'Bicycle and Pedestrian Transportation Unit' was established under a scheme organized by municipality's Department of Transportation. This small unit started with EuroVelo, and then expanded its operation towards development of citywide cycling activities as a part of transportation system (cycling as tourism and recreation, to cycling as transportation).

As a development of EuroVelo perspective, another important EU-wide activity called European Cycling Challenge (ECC) was undertaken in order to develop cycling as a means of transportation. The ECC is the largest competition for urban cyclists' teams, which is won by the city that 'rides' the longest total distance. Being part of the ECC makes cyclists active actors in the planning process. Crowd-sourced data is collected by volunteers to make heat maps, illustrating the most used cycle routes, allowing the planning of cycling networks based on real needs. On behalf of the city of Izmir, the greater municipality joined ECC 2016, but achieved only 17th rank in the competition due to lack of interest by cyclists in the city. However, ECC 2017 was a great success; Izmir was first of 52 cities from 17 countries. The campaign process was actively promoted by the newly established Bicycle and Pedestrian Transportation Unit, which used city-wide advertisements, 
set up pit stop points, organized special cycling events and promotions in local cycling-friendly shops.

Above all, the Platform of Developing Cycling Transportation (BUGEP) was established as an overarching platform with the purpose of recruiting many volunteers, clubs and groups aiming to support the development of cycling infrastructure, promoting the bicycle as mode of transportation and its integration with other modes, and boosting active dialogue and project partnerships between municipal organizations and central government institutions. ${ }^{27}$ BUGEP has become one of the major achievements resulting from Izmir's participation in ECC, and BUGEP's actors actively contributed Izmir's winning performance in the competition.

The second wave of cases implies a locally grown social innovation, which then converted to form a part of EU-induced policymaking process. In this group, many cycling events were organized with diverse groups throughout the city, as the wave of events gained momentum in this decade. The earliest form of these events was the tour known as Thursday Evening Bicyclists [Perşembe Akşamı Bisikletçileri] beginning in 2007. The main motivation of the group was to prove the usefulness of bicycle transportation to city dwellers and local governments. Since then, similar communities such as Friday Evening Bicyclists, and Wednesday Evening Bicyclists have been established. Another group, Contra Cycle [Karşı Bisiklet] was organized to highlight local environmental problems. Since 2010, groups and activists have regularly organized events bearing the globally recognized name of Critical Mass. The aim of these events is to show that the bicycle is a transportation vehicle, and that roads are not only for cars but also for bicycles, and making cycling visible in the city.

Alongside regular events, there are networked single events organized by local cyclist groups, such as Fancy Women Bike Ride [Süslü Kadınlar Bisiklet Turu], aimed at increasing the visibility of women in public spaces. Organized via social media, the ride takes the shape of a parade. Originally a unique event, Fancy Women Bike Ride has been continued since 2013, and spread 10 different cities in Turkey. Additionally, promoting safe cycling use for different groups, the greater municipality has joined EU H2020 Flow Project as an exchange city in 2016. One of the major objectives of this project is to actively support the take-up of congestion-reducing walking and cycling measures by public administrations and promoting the development of the tram and cycling/walking infrastructure enabling safe walking and cycling in the city center. To this end, three FLOW strategies have been developed. The first strategy aims to connect the existing seashore cycling routes to inland areas by developing the cycling transportation network. The second strategy is to connect all schools/campuses and transportation hubs. After these objectives have been achieved, the third aim is to connect the inner city to the rural areas. 


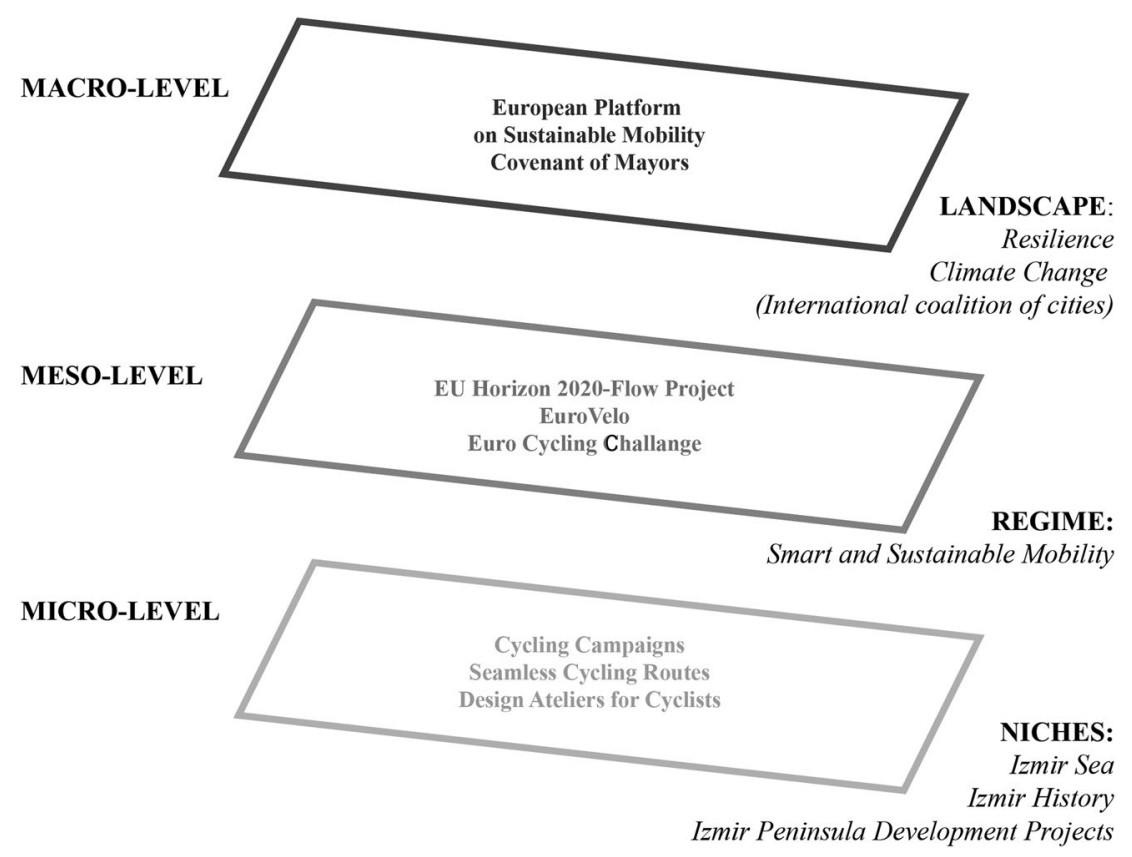

Figure 1. Multi-level perspective of Izmir's cycling case.

The citywide strategy-making process that started with FLOW has recently transformed into the preparation phases of Walking and Cycling Master Plan of Izmir. This plan consists of the components of developing Sustainable Urban Mobility Plans, which contributes to the achievement of the European climate and energy targets. Again with FLOW, micro level transport modeling efforts has developed in line with macro level modeling studies of Izmir's Urban Transportation Master Plan. With the help of closer dialogue between the greater municipality and local cycling groups, cycling design workshops were conducted in 2015 and variety of ideas were approved, including bicycle workshops located at the heart of Evka3 Transportation Hub, resulting from a National level Architectural Design Competition, organically connected to the demo site of FLOW project.

Overall, Izmir is a case study that effectively reflects MLP, governed by local level initiatives in the case of cycling, seen in Figure 1.

\section{Evaluations: environmental policy learning through multi-level perspective in Izmir}

In this section, context factors, i.e. political culture, administrative capacity and deliberative setting that have constrained/enabled glocal policy learning in Izmir are discussed. 


\section{Political culture}

Political culture largely refers to public participation issues and citizen engagement. Renewable energy, energy efficiency, and clean energy technologies have been promoted both in national and the local policy agendas. Izmir's CoM co-signatories support this process, as well as networks such as EU Energy Cities, However, current application of renewable energy investments in Izmir, especially wind energy, are strongly opposed by local environmentalist groups. Unfortunately, learning from the case of cycling implies that engagement strategies for informal bodies, such as groups, platforms, and communities, are weakened by bottlenecks in the silo model of public administration. Departments within governments that exhibit such behavior tend to reject sharing their resources or ideas with other groups, i.e. non-governmental bodies. Thus, collaborations of communities, platforms, and groups with municipalities are less effective, if collaborations do not provide benefits to municipal organizations members. Even the establishment of a Bicycle and Pedestrian Transportation Unit is insufficient to provide the strong linkage between municipal organization and civil society needed to empower the niche actors and bring them into decision-making processes, which would in turn allow them to reconfigure relationships, resources and lines of power. In this regard, the development of BUGEP offers at best transitory progress.

\section{Administrative capacity}

Administrative capacity is another important context factor for learning process. The community of EU expertise is missing in the case of Izmir. There is a need for staff with advanced English to create an effective dialogue with the EU project partners. The EU process is peripheral to most in the municipal government due to the departmental approach taken towards EU projects. Instead, Izmir has exploited the opportunities provided by urban environmental projects, thus, fulfilling local needs and visions. Recent municipal environmental records have identified key internationally funded and EU supported projects, including carbon footprint, nature-based solutions, and sustainable transportation. Governmental hierarchies solely implementing government policies often trump local policies in Izmir. However, local governments and communities are just as capable of developing their own initiative to provide context relevant policies, even though they may not correspond to transnational networks and international problems. On the other hand, environmental problems are seen as global issues, to be managed solely through globally determined and organized processes. Therefore, there is a need for a systemic change in the approach to transportation. ${ }^{28}$ These global pushes have influenced the motivations of international financial/creditor institutions and EU grant schemes aimed at citywide and large-scale green and sustainable development projects. 


\section{Deliberative setting}

The deliberative setting refers to a suitable medium for social learning. It suggests low levels of politicization, frequent exchanges, and partnership relations. In the case of cycling, exchange city position of Izmir in EU H2020 Flow project provides such a setting. Similarly, the newly launched EU H2020 project of UrbanGreenUP, aiming to combat climate change with nature-based solutions, creates a deliberative setting in which each actor (municipality, universities and consultancy firms) act as partners in more horizontal relationships. Niches and strategic niche management have the utmost importance, since they present dynamic alternatives to common practices in Izmir. Although the spatial dimensions of niche innovations are less elaborated, there are practical examples of niche development based on tackling environmental problems in Izmir, particularly in the cycling case. Izmir scales up local experiments towards a global niche through the exchange and sharing of particular pilot projects, e.g. Contra Cycle, Fancy Women Bike Ride. Scaling such initiatives has enabled further social innovations, a gradual process, facilitated by local-global (glocal) learning mechanisms.

In the cycling case, the emergent character of regular activities, special events and local policy efforts confirm learning-by-interacting, and hence social learning. In contrast, EU-induced cycling projects brought instrumental learning and then localized via learning-by-using. By means of niche level social innovations in cycling realignment and reconfiguration types of transition paths are observed, as displayed in Table 1.

Table 1. Learnings from Niche innovations of cycling case of Izmir.

\begin{tabular}{|c|c|c|}
\hline $\begin{array}{l}\text { Glocal Actors (Local \& } \\
\text { International) }\end{array}$ & $\begin{array}{l}\text { Transition Path (transformation, } \\
\text { de-alignment and realignment, } \\
\text { substitution, reconfiguration) }\end{array}$ & $\begin{array}{l}\text { Learning Process } \\
\text { 1. Policy Learning } \\
\text { (Instrumental, Social) } \\
\text { 2. DUl-modes of learning } \\
\text { (learning-by-doing, learning- } \\
\text { by-using, learning-by- } \\
\text { interacting) }\end{array}$ \\
\hline $\begin{array}{l}\text { Global to Local: } \\
\text { ECF Eurovelo Routes, ECF } \\
\text { Euro Cycling Challenge }\end{array}$ & $\begin{array}{l}\text { Realignment: } \\
\text { Cycling tourism, participatory } \\
\text { application process via volunteer } \\
\text { cycling groups; Gamification, } \\
\text { crowd-sourced data collection; } \\
\text { establishment of Bicycle and } \\
\text { Pedestrian Transportation Unit, } \\
\text { BUGEP }\end{array}$ & $\begin{array}{l}\text { Instrumental: } \\
\text { Learning-by-using }\end{array}$ \\
\hline $\begin{array}{l}\text { Local to Global: } \\
\text { Regular Activities and } \\
\text { Specific Events of Cyclists } \\
\text { Groups (e.g. Fancy Women } \\
\text { Bike Ride) }\end{array}$ & $\begin{array}{l}\text { Reconfiguration: } \\
\text { Permitting cycles in public } \\
\text { transportation, design-based } \\
\text { innovation (e.g. bike kitchen via } \\
\text { cycling design workshops), safe } \\
\text { cycling (bike to school campaign); } \\
\text { Attending EU-financed projects like } \\
\text { EU H2020 Flow, Cycling master plan } \\
\text { in line with SUMP }\end{array}$ & $\begin{array}{l}\text { Social: } \\
\quad \text { Learning-by-interacting }\end{array}$ \\
\hline
\end{tabular}




\section{Conclusion}

Izmir has many recently established EU projects and has gained funding for large-scale urban projects designed to scale-up the city to the international level. These changes and consequent learning processes can be understood in terms of transition management literature and social innovation issues. To scrutinize Izmir's glocal environmental policy, this study employs the socio-technical transition approach that emphasizes the role of visions, the development of multi-level governance, and facilitating social learning in the case of cycling policy. Cycling policy that envisions active transportation systems has been extensively promoted in Europe in order to provide urban health and reduce negative environmental impacts. This development has repositioned cycling as an alternative to the current mode of motorized transportation, and this has been echoed in Izmir. In contrast to technology change facilitating economic growth, the context of socio-technical transition in Izmir is now towards sustainable trajectories in the transportation sector through structuring local innovation.

Such local innovation has been found to be possible at three contextual level factors: political culture, administrative capacity and deliberative setting. For political culture, where participation is encouraged, empowering niche actors and inviting them into decision-making processes may restructure relationships and resources. Thus, departments learned to develop suitable projects that fit their needs to regulate the administrative capacity.

In the case of Izmir, the greater muncipality's EU and Grant Projects Directorate should work more closely with other project experts in universities, innovation centers and experienced consultancy organizations. The major disadvantage seems the existence of excessive regulatory protection, which reduced the chance of upscale from the outset. EU-induced projects are valuable because they enhance dialogue and cooperation among the different departments of local organizations, and hence social learning occurred via learning-by-interacting. In this respect, the EU's lab approach could be a possible collaboration opportunity, which may help the establishment of design labs, FabLabs and living labs throughout the city. This may help the creation of body of communities of practice in a shared domain of a deliberative setting. Cycling design workshops, in the case of Izmir, also represent a practical example of transition management: a participatory process of visioning, learning and experimenting. For deliberative settings, as some anecdotal evidence suggests, more EU-induced projects would encourage scaling up to partnerships among the interested parties. Izmir, as a fast-growing city, has many urban problems; therefore, domestic factors may prevail in the short term, but the EU's influence will evolve with over time. Since the implementations are very recent, it is not possible to see long-term results. Positive transitions can be expected in the long run only by creating a social learning environment via learning-by-interacting. 
This paper underlines the importance of environmental policy learning at three levels with the case of Izmir's cycling developments. The findings show that while local policies in Izmir are subject to governmental hierarchies at the landscape level, local governments and communities as niches are completely capable of developing their own initiative to provide context relevant policies, although these may not correspond to transnational networks and international problems. The creation of new trajectories within socio-technical systems on different levels (macro, meso and micro) stimulates a major change within existing science and technology, industries, markets, and politics, and has a considerable impact on built environment and cities as well. Niches can strengthen the drive to bring needed changes. However, despite the high level of social innovation in the given examples, up-scaling niche innovations at a glocal level is not always possible, as this requires configuring transition paths towards a learning city, involving partnering, serving, designing and teaching. All in all, local level improvements and initiatives in Izmir provide channels to realign socio-technical regimes via niche urban innovations.

\section{Notes}

1. Börjesson and Eliasson, "The Value of Time."

2. Davis, Road Transport and Health and Owen et al., "Environmental Determinants."

3. Donaldson, At Least Five a Week.

4. Horton, Rosen and Cox, Cycling and Society; Steinbach et al., "Cycling and the City"; and Horton, Rosen and Cox, Cycling and Society.

5. Fraser and Lock, "Cycling for Transport."

6. Kemp, Schot, and Hoogma, "Technology and the Transition," 182.

7. Smith, Voß, and Grin, "Innovation Studies," 440.

8. Geels and Schot, "Typology of Sociotechnical Transition Pathways."

9. Geels and Frank, "Technological Transitions" and Geels and Frank, "From Sectoral Systems."

10. Geels and Schot, "Typology of Sociotechnical Transition Pathways."

11. Rip and Kemp, "Technological Change" and Geels, Technological Transitions.

12. Geels, "A Socio-Technical Analysis."

13. Diamond, Stein, and Allcorn, "Organizational Silos" and Allcorn and Diamond, "Moral Violence."

14. Gyrd-Jones, Helm, and Munk, "Exploring the Impact".

15. Geels, "A Socio-Technical Analysis."

16. Lundvall, "National Innovation Systems."

17. May, "Policy Learning and Failure."

18. Paavola, "MultiLevel Environmental Governance."

19. Robertson, "Glocalization."

20. Öğretim et al., "A Survey of Best Practices."

21. As of 12 October 2017, as documented by the Metropolitan Municipality of Izmir on its website http://www.izmir.bel.tr/en/News/izmir-is-th-first-city-toparticipate-in-eurovelo-8-from-turkey/30031/162. 
22. Kemp, Schot, and Hoogma, "Technology and the Transition"; Geels and Frank, "Technological Transitions"; and Geels and Frank, "From Sectoral Systems."

23. EEA Report, "Transitions," 87.

24. As of 20 September 2017, CoM - Covenant of Mayors for Climate and Energy documented on its website http://www.covenantofmayors.eu.

25. SEAP, İzmir Büyükşehir Belediyesi.

26. Boğaziçi University, "Türkiye'nin Şehirleri Sürdürülebilirlik Araştırması."

27. As of 19 March 2018, the BUGEP presented on its website http://www.bugep. org.

28. EEA Report, “Transitions,” 87.

\section{Note on contributors}

Koray Velibeyoğlu BSc, MSc, PhD is Associate Professor in the Department of Urban and Regional Planning, Izmir Institute of Technology. He is the director of the Center for Lifelong Learning. His research spans urban design, planning history, knowledge management, local asset-based development, urban ICT policy-making and knowledge-based development processes. He is also the project manager of Izmir Peninsula Sustainable Local Development Project.

Onur Mengi BSc, MSc, PhD is Assistant Professor in the Department of Industrial Design at Izmir University of Economics, Izmir, Turkey. He is Head of the Design Management Masters Program in the Graduate School. His research areas are creative industry ecosystems, design management, design strategies, and placemaking.

\section{Disclosure statement}

No potential conflict of interest was reported by the authors.

\section{Bibliography}

Allcorn, Seth, and Michael Diamond. "Moral Violence in Organizations: Hierarchic Dominance and the Absence of Potential Space." Organisational and Social Dynamics 4, no. 1 (2004): 22-45.

Boğaziçi University. “Türkiye’nin Şehirleri Sürdürülebilirlik Araştırması [Sustainability Research of Turkey's Sustainable Cities].” Report prepared to MasterCard Turkey by Boğaziçi University, Istanbul. Accessed March 12, 2018. http://v3.arkitera.com/UserFiles/File/download/Turkiyenin_Illeri_ Surdurulebilirlik_Arastirmasi.pdf.

Börjesson, Maria, and Jonas Eliasson. "The Value of Time and External Benefits in Bicycle Appraisal." Transportation Research Part A: Policy and Practice 46, no. 4 (2012): 673-683.

Davis, Adrian. Road Transport and Health. British Medical Association: London, 1997.

Diamond, Michael A., Howard F. Stein, and Seth Allcorn. "Organizational Silos: Horizontal Organizational Fragmentation." Journal for the Psychoanalysis of Culture \& Society 7, no. 2 (2002): 280-296.

Donaldson, Liam J. At Least Five a Week: Evidence on the Impact of Physical Activity and its Relationship to Health. UK Department of Health, 2004. Accessed February 
20, 2018. https://www.staffs.ac.uk/images/First\%20steps\%20SHE\%20CMO\% 2520Report\%2520Summary_tcm68-26370.pdf.

EEA (European Environment Agency) Report. "Transitions Towards a More Sustainable Mobility System.” Report No: 34/2016, Luxembourg. Accessed May 22, 2018. https://publications.europa.eu/en/publication-detail/-/publication/ c276880f-9c1a-11e7-b92d-01aa75ed71a1/language-en.

Fraser, Simon DS, and Karen Lock. "Cycling for Transport and Public Health: A Systematic Review of the Effect of the Environment on Cycling." European Journal of Public Health 21, no. 6 (2011): 738-743.

Geels, Frank W. "Technological Transitions as Evolutionary Reconfiguration Processes: A Multi-Level Perspective and A Case-Study.” Research Policy 31, no. 8-9 (2002): 1257-1274.

Geels, Frank W. "From Sectoral Systems of Innovation to Socio-Technical Systems: Insights About Dynamics and Change from Sociology and Institutional Theory." Research Policy 33, no. 6-7 (2004): 897-920.

Geels, Frank W. “The Dynamics of Transitions in Socio-Technical Systems: A MultiLevel Analysis of the Transition Pathway from Horse-Drawn Carriages to Automobiles (1860-1930)." Technology Analysis \& Strategic Management 17, no. 4 (2005): 445-476.

Geels, Frank W. Technological Transitions and System Innovations: A CoEvolutionary and Socio-Technical Analysis. Aldershot: Edward Elgar, 2005.

Geels, Frank W. "A Socio-Technical Analysis of Low-Carbon Transitions: Introducing the Multi-Level Perspective into Transport Studies." Journal of Transport Geography 24 (2012): 471-482.

Geels, Frank W., and Johan Schot. "Typology of Sociotechnical Transition Pathways.” Research Policy 36, no. 3 (2007): 399-417.

Gyrd-Jones, Richard I., Clive Helm, and Jonas Munk. "Exploring the Impact of Silos in Achieving Brand Orientation." Journal of Marketing Management 29, no. 9-10 (2013): 1056-1078.

Horton, Dave, Paul Rosen, and Peter Cox, eds. Cycling and Society. London: Routledge, 2016.

Jordan, Andrew. "The Governance of Sustainable Development: Taking Stock and Looking Forwards." Environment and Planning C: Government and Policy 26, no. 1 (2008): 17-33.

Kemp, René. "Technology and the Transition to Environmental Sustainability: The Problem of Technological Regime Shifts.” Futures 26, no. 10 (1994): 1023-1046.

Kemp, René, Johan Schot, and Remco Hoogma. "Regime Shifts to Sustainability Through Processes of Niche Formation: The Approach of Strategic Niche Management." Technology Analysis \& Strategic Management 10, no. 2 (1998): 175-198.

Lundvall, Bengt-Åke. "National Innovation Systems - Analytical Concept and Development Tool." Industry and Innovation 14, no. 1 (2007): 95-119.

May, Peter J. “Policy Learning and Failure.” Journal of Public Policy 12, no. 4 (1992): 331-354.

Nelson, Richard R., and Sidney G. Winter. An Evolutionary Theory of Economic Change. Cambridge MA: Belknap Press. 1982.

Öğretim, Egemen Ol, Selim Solmaz, Yavuz Bayam, and İbrahim Gürler. "A Survey of Best Practices in Renewable \& Sustainable Energy and Projections to City of İzmir." Accessed May 5, 2018. https://www.researchgate.net/profile/Yavuz_Bayam/ publication/266965141_A_Survey_of_Best_Practices_in_Renewable_Sustainable_ 
Energy_and_Projections_to_City_of_Izmir/links/543fc4c00cf21227a11b7955/ASurvey-of-Best-Practices-in-Renewable-Sustainable-Energy-and-Projections-toCity-of-Izmir.pdf.

Owen, Neville, Eva Leslie, Jo Salmon, and Michael J. Fotheringham. "Environmental Determinants of Physical Activity and Sedentary Behavior." Exercise and Sport Sciences Reviews 28, no. 4 (2000): 153-158.

Paavola, Jouni. "Multi-Level Environmental Governance: Exploring the Economic Explanations." Environmental Policy and Governance 26, no. 3 (2016): 143-154.

Rip, Arie, and René Kemp. "Technological Change." Human Choice and Climate Change 2 (1998): 327-399.

Robertson, Roland. "Comments on the Global Triad and Glocalization: Globalization and Indigenous Culture." Remarks for Globalization and Indigenous Culture Conference, Kokugakuin University, Japan, 1997, Accessed July 10, 2018. http:// www2.kokugakuin.ac.jp/ijcc/wp/global/15robertson.html.

Robertson, Roland. "Glocalization: Time-space and Homogeneity-Heterogeneity." Global Modernities 2, no. 1 (1995): 25-44.

SEAP (Sustainable Energy Action Plan). İzmir Büyükşshir Belediyesi Sürdürülebilir Enerji Eylem Planı [Izmir Metropolitan Municipality Sustainable Energy Action Plan], Sağlıklı Kentler ve Temiz Enerji Şube Müdürlügüu, Izmir. Accessed January 12, 2018. http://www.skb.gov.tr/wp-content/uploads/2017/01/Izmir-BuyuksehirBelediyesi-Surdurulebilir-Enerji-Eylem-Plani.pdf.

Smith, Adrian, Jan-Peter Voß, and John Grin. "Innovation Studies and Sustainability Transitions: The Allure of the Multi-level Perspective and its Challenges." Research Policy 39, no. 4 (2010): 435-448.

Steinbach, Rebecca, Judith Green, Jessica Datta, and Phil Edwards. "Cycling and the City: A Case Study of How Gendered, Ethnic and Class Identities Can Shape Healthy Transport Choices." Social Science \& Medicine 72, no. 7 (2011): 1123-1130. 